\title{
Munchausen by Proxy in Older Adults: A Case Report
}

\author{
Anurita Singh ${ }^{1}$, Mick Coppock ${ }^{1}$, Elizabeta B. Mukaetova-Ladinska ${ }^{1,2}$ * \\ ${ }^{1}$ Newcastle Older People's Liaison Service, Northumberland, Tyne and Wear NHS Foundation Trust, Centre for the Health \\ of the Elderly, Campus for Ageing and Vitality, Newcastle upon Tyne, Tyne and Wear NE4 6BE, UK; ${ }^{2}$ Institute for Ageing \\ and Health, Newcastle University, Campus for Ageing and Vitality, Newcastle upon Tyne, Tyne and Wear NE4 5PL, UK
}

\begin{abstract}
Citation: Singh A, Coppock M, MukaetovaLadinska EB. Munchausen by Proxy in Olde Adults: A Case Report. Maced J Med Sci. 2013 June15;6(2):178-181.

http://dx.doi.org/10.3889/MJMS.1857-5773.2013.0297. Key words: Munchausen by Proxy; Older adults; Dementia; male.

"Correspondence: Dr. Elizabeta B. MukaetovaLadinska, MD, PhD, MRCPsych. Institute fo Ageing and Health, Campus for Ageing and Vitality, Newcastle University $N$ Ageing and Vitality, Newcastle University, Newcastle upo Tyne, Tyne and Wear NE4 5PL, UK. Tel: +44 Elizabeta.Mukaetova-Ladinska@ncl.ac.uk

Received: 25-Mar-2013; Revised: 08-May2013; Accepted: 10-May-2013; Online first: 17-May-2013

Copyright: ๑ 2013 Singh A. This is an openaccess article distributed under the terms of the Creative Commons Attribution License, which permits unrestricted use, distribution, and reproduction in any medium, provided the original author and source are credited.

Competing Interests: The authors have declared that no competing interests exist.
\end{abstract}

\begin{abstract}
The diagnosis of Munchausen by Proxy (MbP) is well recognised with children as the victims, but remains infrequently reported in later life. Older frail adults may also become victims of this syndrome. In this study we report a case of an older adult with a diagnosis of dementia and her son being the perpetrator. We discuss the diagnosis of $\mathrm{MbP}$ in older adults and review the available literature on $\mathrm{MbP}$ for this population. We also highlight the clinical features that should alert the clinicians to this diagnosis as it has considerable impact on the victim's health and consumes disproportionately large health care resource.
\end{abstract}

\section{Introduction}

Münchausen by proxy (MbP) is a factitious disorder characterised by a distinct behavioral pattern in which a caregiver deliberately exaggerates, fabricates, and/or induces physical, psychological, behavioral, and/or mental health problems in people under their care [1]. Although usually associated with child abuse (below the age of 4; [2, 3]), medical and educational neglect [4], and/or social deprivation, older frail adults may also become victims of this syndrome. In the current study we present a case of an older adult with a diagnosis of dementia with her younger son being the perpetrator. We discuss the diagnosis of $\mathrm{MbP}$ in older adults and review the literature to raise the awareness about this syndrome in this population. The lawfulness and ethical processing of the information contained in the current case report was according to the Caldicott principles (Department of Health, 2010; www.dh.gov.uk), and in consultation with the Northumberland, Tyne and Wear NHS Foundation Trust Caldicott Guardian.

\section{Case history}

Mrs X, 79 year old widowed lady, had suffered from dementia with Lewy bodies for three 
years. She lived with her youngest son, who was her main carer, and his partner when admitted to an orthopaedic ward following a fractured hip due to a fall at home.

Table 1: Munchausen By Proxy Diagnostic Criteria. Comparison between the DSM-IV-TR [5] and Mrs X' clinical symptomatology and characteristics of the perpetrator. NA, information not available; Adapted after [6].

\begin{tabular}{|c|c|c|c|}
\hline \multicolumn{2}{|c|}{ DSM-IV-TR MbP Criteria } & \multicolumn{2}{|r|}{ Our case } \\
\hline A. & $\begin{array}{l}\text { The perpetrator } \\
\text { intentionally produces or } \\
\text { feigns physical or } \\
\text { psychological signs or } \\
\text { symptoms in another } \\
\text { person who is under his } \\
\text { or her care. }\end{array}$ & A. & $\begin{array}{l}\text { Worsening of medical and } \\
\text { mental problems induced by } \\
\text { son, overloading fluid and } \\
\text { withholding and changing } \\
\text { dose of medication. }\end{array}$ \\
\hline B. & $\begin{array}{l}\text { The motivation for the } \\
\text { perpetrators is to assume } \\
\text { the sick role by proxy. }\end{array}$ & B. & $\begin{array}{l}\text { Frequent self-referrals to } \\
\text { medical and psychiatric } \\
\text { services, leading to } \\
\text { admissions and } \\
\text { unnecessary investigations. } \\
\text { Son was more worried about } \\
\text { treatments and interventions } \\
\text { than Mrs X. }\end{array}$ \\
\hline C. & $\begin{array}{l}\text { External incentives such } \\
\text { as financial gain are } \\
\text { absent. }\end{array}$ & C. & $\begin{array}{l}\text { No external incentives } \\
\text { underlying son's behaviour. }\end{array}$ \\
\hline D. & $\begin{array}{l}\text { Another mental disorder } \\
\text { such as depression does } \\
\text { not account for the } \\
\text { behaviour. }\end{array}$ & D. & $\begin{array}{l}\text { Son had frequent visits to } \\
\text { GP regarding his } \\
\text { unexplained medical } \\
\text { problems. No overt mental } \\
\text { health problems } \\
\text { documented. }\end{array}$ \\
\hline \multicolumn{2}{|c|}{ Warning signs to alert the clinician* } & \multicolumn{2}{|c|}{ Applicability to our case } \\
\hline 1. & $\begin{array}{l}\text { Unexplainable, persistent } \\
\text { or recurrent illnesses. }\end{array}$ & 1. & $\begin{array}{l}\text { Blaming nursing and medical } \\
\text { staff for Mrs X worsening } \\
\text { symptoms. }\end{array}$ \\
\hline 2. & $\begin{array}{l}\text { Discrepancies in the } \\
\text { history and clinical } \\
\text { findings. }\end{array}$ & 2. & $\begin{array}{l}\text { Worsening of clinical } \\
\text { symptoms and medication } \\
\text { side effects, as described by } \\
\text { son, not witnessed by } \\
\text { medical and nursing staff. }\end{array}$ \\
\hline 3. & $\begin{array}{l}\text { Symptoms and signs } \\
\text { occurring only in the } \\
\text { suspected perpetrators } \\
\text { presence. }\end{array}$ & 3. & $\begin{array}{l}\text { Improvement of medical and } \\
\text { psychiatric symptoms once } \\
\text { son's visits restricted. }\end{array}$ \\
\hline 4. & $\begin{array}{l}\text { Suspected perpetrator is } \\
\text { extremely attentive and } \\
\text { visits or calls constantly. }\end{array}$ & 4. & $\begin{array}{l}\text { Son pays frequent visits, } \\
\text { calls constantly. }\end{array}$ \\
\hline 5. & $\begin{array}{l}\text { Suspected perpetrator } \\
\text { appears more worried } \\
\text { about treatments and staff } \\
\text { interventions than the } \\
\text { person themselves. }\end{array}$ & 5. & $\begin{array}{l}\text { Son was more worried about } \\
\text { treatments and interventions } \\
\text { than Mrs X. }\end{array}$ \\
\hline 6. & $\begin{array}{l}\text { The suspected } \\
\text { perpetrator may have a } \\
\text { history of Munchausen's } \\
\text { (present in about } 25 \% \text { of } \\
\text { cases). }\end{array}$ & 6. & NA \\
\hline
\end{tabular}

She had profound receptive and expressive dysphasia, with intermittent auditory and visual hallucinations causing significant emotional distress. Due to this, she was referred to the Liaison Psychiatry Team for older adults. Her mental states and past medical history revealed that she was on a changing dose of anti-dementia drug (donepezil), with daily varying doses, ranging from $2.5-15 \mathrm{mg}$. Her son controlled the administration of her medication, and it depended on his interpretation of her mental state on the day. According to him, he was advised to do so by a psychiatrist who had seen Mrs X, though there was no record of this. The son had consulted four NHS and private psychiatrists in relation to his mother's condition, each being unaware of the others. He selectively picked out information and recommendations from their assessments (providing various clinical letters, most few years old, containing various advices regarding medication) and used them in discussion with clinical teams, leading to numerous confrontations with medical and nursing staff on the ward over this issue.

Despite Mrs $X$ being on fluid restriction, son was administering her fluids covertly, leading to fluid overload and peripheral oedema. He insisted on knowing all details about clinical assessments and laboratory results, and accessed various departments, cross-checking information, adamant he was authorised for this. He insisted on daily meetings with staff and accessing medical/nursing notes regarding his mother's care. His repeated requests for advice about psychiatric medication and his mother's mental health resulted in our liaison team providing him a daily phone call update and a twice-weekly face-toface meeting

A meeting was held involving Social Services and hospital management, and restrictions were placed on son's visits, with a noticeable improvement in Mrs. X's mood and hallucinations. On transfer to a care home, son increased his direct input into her care again: he visited for prolonged periods, arranging multiple visits jointly with her new GP, requesting investigations for her physical health problems, arranging for his mother's antidepressant medications to be stopped. He was suspicious that a psychiatrist was visiting at night and secretly administering his mother medication.

In a review meeting at the care home, he raised concerns about his mother's fluctuating mental state, with varying auditory and visual hallucinations. This was due to her anti-dementia medication being stopped at his insistence due to side effects (e.g. increased confusion, falls, 'drooling', depression etc.) without any clinical documentation. His older sister provided information that he had been contacting them frequently with worries and concerns about their mother's worsening illness.

At a subsequent meeting with the family, there were multiple disagreements amongst Mrs $X$ son and clinical team about treatment of her dementia, as he thought they were exacerbating her illness. Therefore, all psychotropic and anti-dementia medication was stopped to confirm the latter. Within days following the meeting, Mrs X was admitted to a hospital outside the area due to 'ill health', with a new GP being involved, and a private psychiatric team. No information of prior involvement of psychiatric, medical and social services was disclosed. Although no medical reasons for admission were found, over the following 3 months, several other hospital admissions followed, initiated by Mrs $X$ son, with psychiatric medication being ultimately stopped. 


\section{Discussion}

Mrs $X$ medical state was dominated by frequent involvement with various primary care providers, psychiatric and old age psychiatry teams and acute medical admissions in a number of localities. Although on the last occasion genuine medical reasons for admission were not found, the previous admission to acute medical wards were largely triggered by her worsening cognitive and behavioural problems (e.g. visual hallucinations and depression), and all attempts to regulate them, either via medication, or behavioural management were compromised by her son's involvement. In this respect, the DSM-IV criteria for MbP are fulfilled ([5]; table 1). Please note that the latest revision of the DSM criteria, not yet published refer to $\mathrm{MbP}$ as 'Factiitous Disorder Imposed on Another'.

Verification of MbP especially in older adults poses even greater difficulties than in young children. As the most common form of verification is the resolution of symptoms when the victim and the perpetrator are separated [2], the improvement of Mrs $X$ mental and physical state when her son's visits were stopped provide further confirmation of MbP. However, we failed to obtain the perpetrator's confession about his acts. Nevertheless, his behaviour was also characterised by frequent visits to his GP (up to 40 visits in one year due to various psychosomatic problems, not substantiated with medical investigations). This per sé is in agreement with the documented psychological profile of $\mathrm{MbP}$ perpetrators, with nearly half of them (44\%) having some psychological problems, including depression, personality disorder or psychosomatic problems [7], psychotic disorder including a severe bipolar disorder $[8,9]$ or at least some characteristics suggestive of Munchausen Syndrome, present in up to $30 \%[2,7]$.

To our knowledge, there are only 3 similar $\mathrm{MbP}$ cases published: a 69 year old man with numerous consultations in various specialities at the request of his partner [10], a 73 years old woman with multiple myeloma with recurrent hypoglycaemia without any cause [11] and an 80 years old woman with altered consciousness [12]. In all instances, the perpetrators were females, 2 of them with nursing background, which is in agreement with previous reports of up to one third perpetrators having nursing/medical training and/or experience [13]. In contrast, in our case report, the perpetrator was the son, with no medical or nursing background. Since the majority of the MbP perpetrators are women (77-98\%; [13]), having a male perpetrator is rather unusual and rare (less than $7 \%$ men, as reviewed in [2]). Meadow [7] reported a study on 15 male perpetrators, of which $6(40 \%)$ had psychosomatic problems, similar to Mrs $X$ ' son, and 5 documented Munchausen syndrome.

Older adults are vulnerable to abuse and this is even more for older adults with dementia, bearing in mind their frailty, confusion, and having to rely on support of others. The latest Equality and Human Rights Commission (EHRC) report (November, 2011) on care into home care system in England, highlighted widespread abuse among older people with various mental and physical needs (http://www.equalityhumanrights.com). This further confirms the vulnerability of this population group, and should be borne in mind by all clinicians involved in their care. This becomes especially important when there are repeated admissions to different units with multiple presentations, with relatives or family members who are disproportionally involved especially with the medical treatment. Sharing relevant information among various clinical services and agencies involved in patients' care may help with detection of potential patient abuse, and alert care providers to relatives' unreasonable demands and $\mathrm{MbP}$. As shown in our case, involvement of a Psychiatric Team (medical and nursing staff) is helpful not only in diagnosing the $\mathrm{MbP}$, but also providing support to medical teams and agencies in coping with these difficult situations. Since in medico-legal terms, $\mathrm{MbP}$ represents ' $\mathrm{a}$... descriptive of a behaviour, and not a psychiatrically identifiable illness of condition' (Supreme Court of Queensland, R vs LM, 2004; now also accepted by the UK High Court of Justice), it is 'not advisable to use this label as a substitute for factual analysis and risk assessment' (Mr. Justice Ryder, High Court of Justice, 2005). In many cases, including ours, the perpetrator does not fulfil the criteria for compulsory psychiatric treatment, and to date there is a lack of evidence for efficacy of psychiatric interventions of the perpetrators. We believe, therefore, that the $\mathrm{MbP}$ may be more common than reported, and we hope that this case report will increase the awareness of this form of abuse of vulnerable older adults under our care.

Description of authors' roles: $M C$ and EBM-L were involved in direct patients' care; $M C$ prepared the case report; $A S, M C$ and EML all contributed to manuscript preparation, literature search and writing the article.

\section{References}

1. Lasher LJ. MBP Definitions, Maltreatment Behaviors, and Comments. http://www.mbpexpert.com/basics.htm. 2011 (Retrieved 16 March 2013).

2. Sheridan MS. The deceit continues: an updated literature review of Munchausen Syndrome by Proxy. Child Abuse Negl. 2003; 27:431-451.

3. Vennemann B, Bajanowski T, Karger B, et al. Suffocation and poisoning: The hard-hitting side of Munchausen syndrome by proxy. Int J Legal Med. 2005; 119: 98-102.

4. Stirling J. American Academy of Pediatrics Committee on Child Abuse Neglect. Beyond Munchausen syndrome by proxy: identification and treatment of child abuse in a medical setting. Pediatrics. 2007; 19: 1026-1030.

5. American Psychiatric Association. Diagnostic and statistical 
manual of mental disorders (4th ed., text rev.). Washington, DC, 2000.

6. Schreier HA, Libow JA. Hurting for Love: Muchausen by Proxy Syndrome. The Guilford Press, 1993.

7. Meadow R. Munchausen syndrome by proxy abuse perpetrated by men. Arch Dis Child. 1998; 78:210-216.

8. Del Casale A, Ferracuti $S$, Rapinesi $C$, et al. Factitious disorder comorbid with bipolar I disorder. A case report. Forensic Sci Int. 2012; 219:e37-40.

9. Lazarus A. Factitious disorder in a manic patient: case report and treatment considerations. Int J Psychiatry Med. 19851986; 15:365-9.

10. Smith NJ, Ardern MH. More in sickness than in health': a case study of Munchausen by Proxy in the elderly. J Family Therapy. 1989; 11:321-334.

11. Ben-Chetrit E, Melmed RN. Recurrent hypoglycaemia in multiple myeloma: a case of Munchausen syndrome by proxy in an elderly patient. J Int Med. 1998, 244:175-178.

12. Chodorowsk Z, Anand JS, Porzezińska B, Markiewicz A. Consciousness disturbances: a case report of Munchausen by proxy syndrome in an elderly patient. Przegl Lek. 2003; 60:307-308.

13. Rosenberg DA. Web of deceit: A literature review of Munchausen syndrome by proxy. Child Abuse Neglect. 1987; 11:547-563 